\title{
INTERVENCIÓN ADMINISTRATIVA POR RAZÓN DE LA ACTIVIDAD TURÍSTICA: DE LOS CENTROS Y ZONAS DE INTERÉS TURÍSTICO AL MODELO DEL“MUNICIPIO TURÍSTICO”
}

\author{
FERNANDO LLAGAS GELO ${ }^{1}$ \\ Profesor Asociado Doctor \\ Universidad Córdoba/ Universidad Loyola
}

\section{Resumen}

La Ley de Centros y Zonas de Interés Turístico Nacional de 1963 supuso la puesta en marcha de un modelo de intervención administrativa extraordinariamente lesivo para la ordenación territorial en favor de un desarrollo turístico a ultranza que produjo importantes desequilibrios en las políticas presupuestarias y urbanísticas de muchos municipios. Posteriormente no ha habido una actuación administrativa que pueda equipararse a la propiciada por aquella Ley de 1963. El “municipio turístico" como instrumento de planificación de la actividad turística no puede equipararse a aquel modelo, pero en buena medida, sí supone, como instrumento de intervención administrativa, la anteposición de intereses económicos coyunturales a la defensa y preservación de bienes y valores de capital importancia para el desenvolvimiento, en términos sostenibles, de pueblos, ciudades y regiones.

\begin{abstract}
Palabras Clave: Derecho, Turismo, Ordenación turística, Planificación administrativa.

\section{Abstract}

The "1963 Act of Centers and Zones of National Tourist Interest" embodied the implementation of an administrative intervention model which was extremely damaging to territorial planning as it was in favor of an unfettered development of tourism that produced important imbalances in many towns' budgetary and urbanistic policies. There has been no subsequent administrative activity that could be equated with that promoted by the 1963 Law. The "tourist town" as an instrument for planning touristic activity cannot be compared with that model, but, to a certain extent and as a tool for administrative intervention, it does imply the anteposition of short-term economic interests to the defense and preservation of goodsand values of vital importance to the sustainable development of towns, cities and regions.
\end{abstract}

Key Words: Law, Tourism, Tourist management, Administrative planning.

\section{Introducción}

Pudiera cuestionarse la oportunidad y actualidad de abordar cuestiones relativas a los Centros y Zonas de Interés Turístico creados al amparo de una ley publicada hace más de cuarenta años, que perdió efectivamente parte de su eficacia tras la Constitución de 1978 y

\footnotetext{
${ }^{1}$ dt1llgef@uco.es. Profesor de Política Turística en la Universidad de Córdoba y de Derecho Administrativo en la Universidad Loyola.
} 
que fue formalmente derogada en el año 1991. No obstante, aquel instrumento de política turística llamado a canalizar el extraordinario crecimiento del sector turístico del que fue objeto España en los años cincuenta y sesenta nos da la oportunidad de plantear una reflexión sobre la intervención administrativa en el mercado en general y en el turismo en particular en momentos de expansión económica con la finalidad de ordenar el crecimiento promovido por la iniciativa privada. Este aspecto confiere a la reflexión que se plantea una extraordinaria vigencia, a la vista de las cifras de crecimiento de la actividad turística que volvemos a experimentar en Andalucía en particular y en el resto de España en general.

La vigencia de la que hablamos viene también justificada porque, si bien es cierto que la Ley de Centros y Zonas de Interés Turístico Nacional (en adelante, LCyZITN) se promulgó y derogó hace años, sus efectos perduran hoy día. Existen en la actualidad muchos Centros de Interés Turístico en España y especialmente en Andalucía. Se trata de enclaves de población que generan notables desequilibrios en los municipios en los que se encuentran, que son preciso abordar y para los que no existe una respuesta adecuada y precisa que haya previsto situaciones de esta índole, toda vez que la normativa local y urbanística en vigor no está pensada para un crecimiento urbano en razón del turismo, por y para el turismo y al margen de las pautas y cauces de la normativa urbanística.

Desde estas premisas abordaremos brevemente las circunstancias del mercado turístico en las que vio la luz la LCyZITN, indagando en la problemática a la que estaba llamada a dar respuesta y cuáles eran los objetivos reales perseguidos con los instrumentos jurídicos que se creaban. Al hilo de estas consideraciones y separándonos un tanto de alguna doctrina que ha analizado la Ley y su reglamento de desarrollo haremos una consideración sobre la naturaleza y el momento histórico del Ordenamiento jurídico que los vio nacer, pues no de otra manera es posible valorar la eficacia y bondad de la norma.

Posteriormente haremos una consideración sobre el contenido de ambas normas desde su consideración como instrumentos de política turística y también de ordenación y gestión del territorio y de los servicios públicos que sobre el mismo han de prestarse tras la culminación del proceso urbanizador, todo ello para encontrar diferencias y similitudes con la actual política turística, más concretamente con el instrumento del "municipio turístico" previsto en la Ley del Turismo de Andalucía y otras leyes de Comunidades Autónomas.

Aquella Ley y Reglamento de los años sesenta tuvieron un discurrir histórico peculiar, porque excepcional era su contenido. Tras su nacimiento hubieron de convivir con la Ley del Suelo de 1956 y luego con la Ley del Suelo de 1975 y con la normativa sobre régimen local posconstitucional, hasta que en 1991 fueron derogados, formalmente porque de facto ya habían perdido toda o casi toda su virtualidad jurídica por el nuevo reparto de competencias y organización territorial del Estado previstos en la Constitución.

\section{El extraordinario crecimiento del sector turístico en España en los años cincuenta y sesenta.}

La España franquista de la posguerra tomó conciencia, quizás ya a finales de la década de los cuarenta, de que la autarquía económica a ultranza no era sostenible y trató de encontrar un equilibrio entre la férrea conservación de los principios que habían auspiciado la rebelión militar y el posterior nacional-catolicismo, amén de una cierta integración en el espacio económico vecino, de rápida recuperación y crecimiento en el que por las sanciones internacionales no participábamos. 
Al comienzo de la década de los cincuenta el turismo se atisbaba ya como fuente de ingresos muy prometedora, no solo por las rentabilidades que proporcionaba, sino porque estas se materializaban en divisas, muy preciadas para las necesidades de nuestro comercio exterior. Por otra parte el turismo era objeto de desconfianza. Si ya de por sí el turismo interior era objeto de importantes controles administrativos, los desplazamientos desde el extranjero, en una España preocupada por la imagen exterior, era objeto de toda suerte de suspicacias. Todas ellas serían vencidas sin embargo por los primeros resultados económicos de un crecimiento que parecía no tener límites y que estaba llamado a poner remedio a las graves deficiencias y desequilibrios que aquejaban a nuestra economía, que ya había perdido el carro de la industrialización en el siglo XIX y que estaba llamada a quedarse fuera de la modernización que experimentaban otros países tras el fin de la Segunda Guerra Mundial.

En este escenario, la administración franquista creó en 1951 el Ministerio de Información y Turismo. Su dotación era escasa e incluso su financiación procedía casi en exclusiva de la llamada "póliza turística" que gravaba las pernoctaciones en una infraestructura hotelera muy exigua, casi la que se había heredado del escenario bélico recién cerrado. La creación del Ministerio no era consecuencia de una opción firme por el desarrollo turístico, sino más bien respuesta a una actividad turística incipiente conformada por clases altas y visitantes esporádicos que no demandaban infraestructura específica alguna. El modelo tenía similitudes con la anterior ordenación de los tiempos de Alfonso XIII, la Dictadura de Primo de Rivera y la Segunda República.

A mediados de la década de los cincuenta la situación económica española era insostenible. La inflación era galopante, la moneda tenía un valor artificial y la balanza de pagos un déficit estructural inevitable porque no se podía prescindir de bienes y recursos del mercado exterior, principalmente del petróleo. En este escenario de casi recesión, descrito en el Primer Plan de Estabilización de 1959, las reservas de divisas se agotaban y el colapso económico era inminente si no se adoptaban medidas de abierta liberalización de la economía y de fin de la autarquía de posguerra. Dos de esas medidas fueron, en lo que ahora nos interesa, una cierta liberalización del comercio exterior y la devaluación y unificación del tipo de cambio de la peseta, que pasaría de un cambio de 42 pesetas-dólar a 60 pesetas-dólar.

La aplicación de las medidas contenidas en el Plan de Estabilización de 1959 produjo un extraordinario crecimiento en la economía española, en el cual tendría un destacado protagonismo el sector turístico. Una vez más, y no sería la última, solucionábamos nuestros problemas económicos estructurales con remedios puntuales y coyunturales, con agotamiento de los recursos que fueran menester. La devaluación de la peseta abarataba extraordinariamente la oferta, con relación a una demanda que experimentaba unas tasas de crecimiento muy elevadas y con visos de estabilidad, lo que resultaba muy propenso al consumo turístico. El clima de apertura nos hacía partícipes, aun residualmente, del crecimiento internacional de nuestros vecinos más inmediatos. El crecimiento industrial que experimentaba la Europa del Mercado Común, encontraba un centro de vacaciones en las costas mediterráneas españolas. Era un turismo que demandaba un escenario muy concreto, de sol y playa, que exigía importantes actuaciones transformadoras del territorio y de las ciudades y municipios costeros, muchos de los cuales perderían su imagen e identidad para volcarse sin denuedo en la actividad turística. De unos seis millones de turistas en el año 1960, cerraríamos la década con más de treinta millones de visitantes.

Simultáneamente, en la misma década, nacía la Escuela Oficial de Turismo, por Decreto 2427/1963, de 7 de septiembre, que preveía la creación de Centros no oficiales de 
formación, que podrían impartir enseñanzas turísticas previa homologación por parte del todopoderoso Ministerio de Información y Turismo.

Se hacía precisa entonces una norma que agilizara la transformación del territorio para la implantación de enclaves turísticos desde una doble perspectiva: la del fomento de la actividad, facilitando los trámites y requisitos para la urbanización y la del control de esa actividad, la turística, que arrojaba unas tasas de crecimiento imparables y que estaba empezando a transformar grandes espacios en un proceso que demandaba control.

\section{El Ordenamiento jurídico franquista de los cincuenta: de la legitimación del origen a la legitimación por el funcionamiento: el nuevo derecho administrativo.}

No es posible hacer una valoración de una norma jurídica, del grado de eficacia desplegado con relación a los fines previstos, sin tener en cuenta el Ordenamiento jurídico en el que se promulga. La ley como fuente del derecho es emanación del poder legislativo que reside en un parlamento que no es tal, si no tiene el respaldo de la ciudadanía materializado en la elección libre de sus miembros, no puede controlar la acción del gobierno y no puede aprobar el gasto que será objeto de ejecución por el ejecutivo. No es posible el análisis de una norma llamada ley sin saber si estamos en presencia de una disposición emanada del poder legislativo propiamente dicho. La LCyZITN no puede abordarse desde las mismas premisas que abordaríamos el estudio de una norma legal posconstitucional, sino desde el presupuesto de estar en presencia de una norma dictada desde un poder único, en el que poder legislativo y ejecutivo se confunden y en el que el poder judicial no cumplía con plenitud su función de garantizar el sometimiento de la actividad administrativa al imperio del Ordenamiento jurídico.

Desde este presupuesto, es pertinente hacer un acercamiento al Ordenamiento jurídico del tiempo en que vio la luz la norma de la que a renglón seguido nos ocuparemos, aunque solo sea para desterrar del análisis la dualidad regulación legal frente a grado de cumplimiento por la actividad administrativa de desarrollo y aplicación del mandato legal.

Haciendo uso de los términos acuñados por la profesora Aguilar Fernández ${ }^{2}$, durante la década de los cincuenta el sistema franquista se empeña por legitimar el Ordenamiento jurídico abandonando la "fundamentación por el origen” en pos de la "fundamentación por el ejercicio" de la ley, a falta de legitimidad democrática que sirva de cimentación al mismo. Esta nueva vía encontraba acomodo en las nuevas tesis tecnócratas que auspiciaron el gobierno franquista de 1957, definitivamente impulsor de una serie de medidas normativas tendentes a la reforma económica de España.

Sobre la verdadera naturaleza del sistema político español en la época objeto de nuestro estudio resulta revelador el informe de la Comisión Internacional de Juristas de 1962 que puso de manifiesto la evidente contradicción del sistema jurídico español con las bases más esenciales del Estado de Derecho y las garantís inherentes a la vigencia efectiva de la división de poderes. Pero en este escenario, el Comité destacaba la presencia de una realidad insoslayable: la existencia de un sistema jurídico administrativo de alta calidad técnica dotado

${ }^{2}$ AGUILAR FERNÁNDEZ, P.: Memoria y olvido de la Guerra Civil española, Alianza. Madrid, 1996. 
de un sistema de garantías muy notable para el administrado ante la actividad digamos ordinaria de la Administración pública.

Efectivamente en la década de los cincuenta se promulgaron normas jurídicoadministrativas auspiciadas por la Sección de Reforma de la Administración dirigida por el Prof. García de Enterría. Vieron la luz en aquella década la Ley de la Jurisdicción Contencioso Administrativa de 1956, la Ley de Régimen Jurídico de la Administración del Estado de 1957 y la Ley de Procedimiento Administrativo de 1958 que procuraban, en aquel escenario de generalizada falta de garantías, legitimidad y vigencia de derecho fundamentales y libertades públicas, un sistema de control y revisión de la actividad ordinaria de la Administración.

Este control no amparaba de forma efectiva la actuación del poder público, sometido a una ley que como hemos apuntado no era tal. Como afirmaría el Prof. Elías Díaz ${ }^{3}$, en ese contexto autoritario, el imperio de la ley no significaba otra cosa que imperio de la voluntad absoluta del ejecutivo no controlado por poder legislativo alguno, ni judicial en sus decisiones de más hondo calado político y económico.

Desde esta premisa, cualquier juicio de la LCyZITN debe estar desprovisto del análisis propio de una norma legal que enmarca una posterior actividad administrativa, normativa y ejecutiva, y sí debe ser valorada como un todo integrante de un proceder del poder público en la gestión de unos recursos, el territorio esencialmente, para el desarrollo de un sector, el turístico, que estaba llamado a atraer importantes ingresos a una economía mermada por los desequilibrios y la ineficacia.

\section{La Ley de Centros y Zonas de Interés Turístico y su Reglamento como instrumentos de intervención administrativa en el mercado.}

El objetivo de la Ley de Centros y Zonas de Interés Turístico era la "ordenación turística del territorio nacional por medio de la planificación y desarrollo de Centros y Zonas de Interés Turístico" (art. 1), lo que puede ser traducido como el establecimiento de un régimen especial en la ordenación del territorio para procurar el fomento de la actividad turística mediante dos instrumentos concretos: unos centros o enclaves urbanos por razón de la actividad turística y unas zonas, conformadas por varios centros, que iban a disfrutar de este régimen excepcional.

Esta planificación de la actividad económica mediante el establecimiento de instrumentos excepcionales no fue única en el sector turístico, sino que se produjo también en el sector industrial mediante las Normas de Ordenación Provisional de los Territorios de los Polos de Promoción y Desarrollo Industrial, aprobadas por Orden de 22 de Septiembre de 1964 del Ministerio de la Vivienda (BOE No 239, de 5 de Octubre de 1964). Los rápidos rendimientos esperados del turismo hicieron no obstante que este fuera preeminente frente a otros sectores y así el art. 18 de la LCyZITN establecía que tras la declaración de un Centro o Zona de Interés Turístico las industrias debían "efectuar las correcciones precisas en sus instalaciones, a fin de acomodarse en su funcionamiento al interés turístico. De no ser ello técnicamente posible, gozarán, para su traslado, de los beneficios que les puedan ser

\footnotetext{
${ }^{3}$ DÍAZ GARCÍA, E.: Estado de Derecho y sociedad democrática, Edicusa. 4a edición. Madrid, 1972,
} 
aplicables y que esta ley establece, pudiendo llegarse, si fuere preciso, a su expropiación forzosa”. Era, en definitiva, un "todo por el turismo".

La Ley tuvo una tramitación difícil ${ }^{4}$. El Ministerio de Información y Turismo elaboró un texto que invadía competencias del Ministerio de la Vivienda ya que implicaba la aprobación de planes de urbanismo como instrumento para la creación de los Centros. Ante esto, la Dirección General de Urbanismo manifestaría su oposición a la Ley con el argumento de que la reciente Ley de Régimen del Suelo y Ordenación Urbana de 1956preveía el planeamiento general y parcial, que podían ser cauces adecuados para atender las necesidades del desarrollo del sector turístico. Finalmente el Ministerio de Información y Turismo, con Manuel Fraga Iribarne al frente, sacó adelante la regulación que institucionalizaba el sacrificio del territorio como bien común para atender las acuciantes necesidades de la situación económica del momento.

El régimen general con respecto al que la LCyZITN hacía excepción venía configurado por la normativa urbanística y por el sistema de distribución de competencias en la ordenación del territorio, que resultaba alterado en favor del Ministerio de Información y Turismo, así como por permitir abiertamente la posibilidad de inversiones extranjeras en España. Quedaban con valor meramente supletorio normas tan capitales como la de Régimen del Suelo y Ordenación Urbana de 1956, la de Régimen Local de 1955 y la de Defensa del Patrimonio Artístico Nacional de 1933.En concreto, las posibilidades que deparaba la Ley del Suelo de 1956 como instrumento de ordenación urbanística capaz de dar respuesta a la actividad turística quedaron grandemente mermadas, cuando no aniquiladas, por la regulación excepcional contenida en la LCyZITN, al amparo de la cual no solo podían planificarse asentamientos turísticos, sino también establecer su ubicación e incluso transformar asentamientos ya existentes. Y todo ello pese a que la Ley del Suelo de 1956 preveía la posibilidad de que mediante planes especiales se pudiera abordar “...la ordenación de ciudades artísticas, protección del paisaje y de las vías de comunicación, conservación del medio natural en determinados lugares, saneamiento de poblaciones y a cualesquiera otras finalidades análogas" (art. 13) y estableciera la protección de "Bellezas naturales en su complejo panorámico o en perspectivas que convienen al fomento del turismo” (art. 15 a.)

La LCyZITN preveía un íter complejo en la configuración de los espacios turísticos en los que se sucedían instrumentos declarativos, de ordenación y planificación del territorio y actividades. La declaración de Centro de Interés Turístico se producía inicialmente tras la tramitación de un procedimiento por resolución del Consejo de Ministros. Una vez obtenida la declaración podía procederse a la elaboración del Plan de Promoción Turística del Centro. Se trataba de un instrumento de planeamiento de la actividad turística. Después de dicha declaración debía redactarse el Plan de Ordenación Urbana del Centro. Hay que significar que conforme al art. 12.1 de la aludida Ley, para la redacción de los Planes de Ordenación Urbana de los Centros era necesario tener en cuenta, además de los principios y normativa de la Ley del Suelo aplicable, la posible existencia de otros, urbanísticos, monumentales o de obras públicas, ya aprobados. Por último, el Consejo de Ministros podía llevar a cabo la declaración de "Interés Turístico Nacional” del Centro. Esta declaración a su vez llevaba aparejadas la ejecutoriedad de los Planes de Promoción Turística y de Ordenación Territorial y Urbana aprobados y el otorgamiento por parte de la Administración Central o Local de las

\footnotetext{
${ }^{4}$ BAYÓN MARINÉ, F (Dir) et al. "Política turística”, en 50 años del turismo español. Un análisis histórico y estructural, Editorial Centro de Estudios Ramón Areces, Madrid 1999.
} 
autorizaciones y licencias que se solicitaran para las obras, construcciones, instalaciones, servicios y actividades de conforme a los respectivos planes.

Como puede colegirse, de esta mezcla de normas, urbanísticas por un lado, de fomento y ordenación del turismo por otro y de control de actividades económicas no podía surgir nada bueno... Y nada bueno surgió, por mucho que queramos hacer un juicio positivo a la vista de lo que hubiera sucedido en el caso de no disponer de regulación alguna sobre la materia. Este régimen de promoción y ordenación turístico no era único, pero sí el que más intensa intervención, no comparable a otros instrumentos de política turística como el Decreto 2482/1974, de 9 de agosto, que creó los territorios de preferente uso turístico.

Ciertamente el crecimiento del sector era imparable, y la capacidad de la realidad económica española para controlarlo era muy escasa, por las dificultades por las que atravesaba, a las que nos hemos referido; pero lo cierto es que la política puesta en marcha estaba llamada a generar graves problemas de desorden y falta de articulación territorial. El orden perdido, fruto de anteponer las necesidades de un sector económico por encima de un recurso fundamental como era el territorio (y no digamos el medio ambiente) no se recuperó en parte hasta la Reforma de la Ley Sobre el Régimen del Suelo de 2 de Mayo de 1975 y luego con el Texto Refundido aprobado por Real Decreto 1346/1976 de 9 de Abril de 1976 que en la Disposición transitoria Quinta 41 establecía que "Los planes relativos a Zonas o Centros de Interés Turístico, que se tramiten al amparo de su legislación específica, deberán ajustarse a las determinaciones de los planes previstos en la presente ley, sin perjuicio de las especialidades que hayan de contener con arreglo a su finalidad”.

La exposición de motivos de la Ley reconocía ya en 1963 la existencia de "fenómenos de saturación y agobio en determinadas zonas y localidades del territorio nacional más favorecidas por la afluencia de visitantes”. Saturación y agobio en las zonas más "favorecidas" que se pretendían solucionar mediante la "pronta adecuación de nuestro equipo turístico receptor y de la programación y ejecución de las correspondientes obras de infraestructura". En definitiva, se trataba de hacer lo posible para encajar la ingente afluencia de turistas, adoptando las medidas que fueran menester y el gasto necesario para su implantación ${ }^{5}$.

Se trataba, y seguimos parafraseando la exposición de motivos de la Ley, de que el "olvido de estos problemas pudiera originar la contracción de las corrientes turísticas que afluyen a nuestra Patria a consecuencia tanto de la incapacidad de los servicios receptivos como de los comunitarios, especialmente los de abastecimientos de agua, urbanización, saneamientos y otros cuyas deficiencias puedan causar un gran perjuicio a nuestro crédito turístico. "Lógicamente ninguna consideración existía sobre la posibilidad de que los destinos hubieran alcanzado su límite de carga y sencillamente limitar la afluencia seleccionando las cuotas de mercado más rentables.

En los primeros años de la década de los sesenta la preocupación medioambiental era nula, no solo en España, sino en el resto de países de nuestro entorno. Tampoco la sostenibilidad ambiental o paisajística era una preocupación de la Ley. La exposición de motivos apuntaba solo a la existencia de "amplias zonas dotadas por la naturaleza de suficientes atractivos para convertirse en turísticas, pero cuyas posibilidades no están

\footnotetext{
${ }^{5}$ FERNÁNDEZ ÁLVAREZ, J. (1965): «La Ley de Centros y Zonas de Interés Turístico Nacional», en Problemas técnicos, económicos y jurídicos de urbanización de zonas turísticas, Instituto de Estudios Turísticos, Vol II, pp. 211-255.
} 
suficientemente desarrolladas, por diversas razones, entre las que sobresale, principalmente, la de la ausencia de una política de fomento que ordene, estimule o supla la iniciativa privada de una manera eficaz y facilite su adecuada explotación turística."

Para la consecución de una más intensa explotación turística la Ley contemplaba dos instrumentos: la declaración de Zonas y Centros de Interés Turístico Nacional y la declaración de "Interés Turístico Nacional”, pero integraba en el sistema la regulación del planeamiento y la ejecución urbanística y la actividad administrativa de control de actividades económicas que resultaban sometidas a las determinaciones de ambas declaraciones. Se trataba, como vimos, de proceder a una "ordenación turística del territorio nacional por medio de la planificación y desarrollo de Centros y Zonas de Interés Turístico” (art. 1).

Los Centros de Interés Turístico eran "áreas delimitadas de territorio que, teniendo condiciones especiales para la atracción y retención del turismo, son, previa su declaración como tales, ordenadas racionalmente en cuanto a la urbanización, servicios e instalaciones precisas para su mejor aprovechamiento. "Era una definición muy indeterminada que se materializaba en la concurrencia de unos requisitos que solo eran tales aparentemente porque la Ley los refería a un futuro: “cuando puedan concurrir en los mismos[los Centros] las siguientes condiciones..."Estas eran: una capacidad mínima de quinientas plazas en alojamientos turísticos, una superficie no inferior a diez hectáreas y unos servicios adecuados (sic) a su capacidad de alojamiento. La indefinición era absoluta al establecer una superficie como criterio, ya que podían declararse Centros de Interés Turístico en un enclave de población ya existente, o en parte del mismo, o en un conjunto de núcleos o en otros de nueva creación (urbanizaciones y complejos) con el único requisito de que su superficie fuese superior a esas diez hectáreas.

A la absoluta indeterminación del concepto, se unían unos requisitos, de futuro, que fácilmente podían cumplimentar cualquier proyecto urbanístico. Pero es más, la Ley preveía que no era necesaria la concurrencia de estas "condiciones” cuando, a juicio del Gobierno, concurrieran circunstancias excepcionales. Puede apreciarse que la eficacia normativa de la Ley, sus facultades para ordenar y controlar la actividad administrativa futura eran nulas ${ }^{6}$, no solo por su origen sino por su contenido.

La norma tenía la intención de crear nuevos enclaves previendo que la calificación de "Centro de Interés Turístico Nacional” no fuera concedida a áreas incluidas en cascos urbanos, salvo cuando por circunstancias topográficas o geográficas aparezcan claramente delimitados (sic), y ha de entenderse que se refería al mismo Centro y no al casco urbano, o cuando se tratara de conjuntos monumentales o de sectores históricos o artísticos, previo informe favorable de la Dirección General de Bellas Artes. La cautela tenía fundamento en no interferir en la ordenación urbanística de los núcleos urbanos.

El expediente podía iniciarse de oficio (por el Ministerio de Información y Turismo) o a instancia de persona interesada, entre las que la Ley relacionaba a otras administraciones... y a promotores privados. El inicio del expediente podía determinar incluso la posibilidad de

\footnotetext{
${ }^{6}$ IVARS VAIDAL, J. A., Planificación turística de los espacios regionales en España, Síntesis, Madrid. 2003. "El enfoque físico, en tanto supone la integración de la planificación sectorial turística con la ordenación del territorio, ha sido ampliamente reivindicado desde diferentes trabajos científicos y técnicos pero no ha existido en la práctica. La política centralista, cuando no marginó la dimensión territorial de la planificación turística, instrumentó a favor del crecimiento urbano-turístico, como demuestra la aplicación de la Ley de Zonas y Centros de Interés Turístico Nacional."
} 
interesar del Ministerio de la Vivienda, que debía acordarlo necesariamente, la aplicación con carácter provisional de las normas previstas en la Ley del Suelo para restringir o suspender la edificación en el Centro o Zona en curso de declaración.

La declaración se hacía en función de la concurrencia de una serie de parámetros que pueden deducirse de la documentación que debía acompañarse cuando la declaración de Centro acontecía a instancia de una persona interesada. Los relacionaba el art. 25 del Reglamento de la Ley:

a) Situación geográfica del área objeto de la actuación.

b) Su delimitación, con indicación de linderos, propiedades colindantes y extensión superficial.

c) Estado y situación jurídica de los terrenos, indicando las áreas propias aportadas de posible expropiación, propiedades públicas, servidumbre, etc.

d) Esquemas de accesos desde las carreteras existentes, como asimismo de los servicios urbanísticos, agua, energía eléctrica, saneamiento, comunicaciones telefónicas y telegráficas, servicios religiosos, sanitarios, comerciales y otros complementarios, todos ellos existentes o a crear en su caso.

e) Servidumbres a establecer o expropiaciones a realizar para las instalaciones de los anteriores servicios o, en su caso, acuerdo con los afectados.

f) Estado de salubridad y sanitario del área, mediante certificación de las autoridades sanitarias que corresponda por razón del lugar.

g) Relación de las industrias existentes, con expresión de las correcciones a introducir en éstas y de las que tuvieron que trasladarse o ser expropiadas, señalando asimismo las indemnizaciones que en todos estos supuestos estuvieron dispuestos a abonar a cada una.

h) Etapas y plazos en que se propone ejecutar el plan.

i) Beneficios que se soliciten entre los previstos en la Ley y legislación complementaria.

j) Referencia a los Planes de Ordenación, de toda índole, aprobados o en trámite, que afecten al área de la actuación.

La resolución de declaración de Centro de Interés Turístico tenía un contenido meramente declarativo ya que la operatividad de la misma se pondía de manifiesto con la ordenación urbanística del Centro y con la aprobación del Plan de Promoción Turística, que había de redactarse en un plazo brevísimo, no superior a treinta días tras la declaración. El Plan tenía el siguiente contenido:

a) Extensión superficial y delimitación, con precisa indicación de linderos.

b) Número mínimo y máximo de alojamientos turísticos que se construirán y de los existentes, en su caso, con indicación de su densidad.

c) Proporción entre las distintas clases y categorías de alojamientos turísticos previstos, atendiendo a las directrices que a tal fin le sean señaladas.

d) Instalaciones y servicios imprescindibles como saneamientos, accesos y comunicaciones. 
e) Determinación, en líneas generales, del estilo, volumen y densidad de las construcciones, atendiendo a su adecuación al paisaje y tradición artística del lugar.

f) obras para modificar o embellecer el paisaje, en su caso. amortización.

g) Estudio económico detallado, sistemas de financiación y plazos de

h) Expresión concreta de las correcciones a introducir en sus instalaciones por parte de las industrias ya existentes en el Centro, con detalle de su importe económico y fundamentación técnica, así como de las indemnizaciones que hayan de abonarse a cada una, especificando, incluso, la indemnización que corresponda a cada industria, en caso de traslado.

Una vez aprobado y publicado el Plan de Promoción Turística del Centro, se podía proceder a la redacción del Plan de Ordenación Urbana en el plazo que la Orden de aprobación determinara, de acuerdo con los principios y normas de la Ley del Suelo. Si los promotores renunciaban a la elaboración del Plan o no lo presentaban en el plazo fijado, la Administración podía hacerlo por sí misma, de oficio. La norma señalaba también el contenido que debía contemplar el Plan, en sintonía con los propios de dicho instrumento de planeamiento. Una vez redactado el Plan de Ordenación Urbana, era remitido por el Ministerio de la Vivienda al de Información y Turismo que era el que en unión con el expediente de declaración del Centro y de aprobación del Plan de Promoción Turística procedía a la elaboración de la propuesta de decreto de declaración de Interés Turístico Nacional del Centro con aprobación de su Plan de Ordenación Urbana. En el decreto de declaración se determinaban expresamente los beneficios que se pudieran conceder para la ejecución de los proyectos, obras y servicios incluidos en el Plan del Centro.

De la sucinta relación que hemos hecho del procedimiento puede desprenderse la absoluta preeminencia del interés turístico en la conformación de la actividad administrativa. En primer lugar se reconoce la capacidad para iniciar el expediente a una amplísima variedad de administraciones, asociaciones de interés económico y promotores en general. Por otro lado se diseña un devenir procedimental en el que el interesado va constatando la posición de la Administración en la resolución definitiva del expediente, que se ultima mediante la aprobación de un instrumento de planeamiento privilegiado, al que se acompaña de importantes beneficios y de una reforzada ejecutividad. La tramitación del expediente en su conjunto, la adopción de muchas de sus resoluciones y la propuesta de resolución de la resolución definitiva se residenciaba en la Administración turística, el Ministerio de Información y Turismo, que lógicamente tendía al cumplimiento de sus competencias de promoción y fomento del turismo removiendo los obstáculos que pudieran impedir o dificultar los proyectos.

Los beneficios que llevaba aparejada la declaración de "Interés Turístico Nacional "eran extraordinarios: la ejecutoriedad inmediata del Plan de Promoción y del Plan de Ordenación Territorial y Urbana aprobados y la obligatoriedad de los mismos para la Administración y los particulares lo que en concreto suponía el otorgamiento de las licencias necesarias para las obras, construcciones, instalaciones, servicios y actividades concretamente previstas o incorporadas a los respectivos Planes. También suponía el otorgamiento de las autorizaciones para el uso y disfrute de los bienes de dominio público o del Estado y de las Corporaciones Locales. Y, quebrando los tradicionales principios autárquicos que habían movido el régimen durante años, la excepción en el régimen de prohibición de adquisición de bienes por extranjeros. 
Se trató en definitiva de plegarse a las acuciantes necesidades económicas generadas por un modelo económico insostenible, poniendo las bases de otro también insostenible porque anteponía los intereses coyunturales de un sector por encima de la gestión de recursos esenciales, como la ordenación territorial y medioambiental ${ }^{7}$.

Una valoración del resultado de esta política turística, la materializada en los Centros, ha merecido en la literatura científica diversas apreciaciones ${ }^{8}$. En general se considera que sirvieron para encauzar en la medida de lo posible el desaforado desarrollo en curso que estaba ocasionando ya notables situaciones de colapso, como la misma Ley reconocía en su exposición de motivos. Pero lo cierto es que basta con echar una mirada a la situación de nuestro litoral para comprobar que tal encauzamiento y contención no se produjo, porque el instrumento de política turística no fue acompañado de un rígido control de planeamiento y la ejecución urbanística que hubiera permitido un control del consumo de territorio y de la degradación paisajística.

Tampoco redundó en instrumento para la ubicación de la actividad turística en emplazamientos predeterminados por razones territoriales, de eficacia de las redes de transportes y disponibilidad de recursos. Los Centros se ubicaron en aquellos emplazamientos que la iniciativa privada, en muchos casos capital extranjero, decidía, sin que ello fuera acompañado de las necesarias inversiones en infraestructuras de acceso, abastecimiento, etc, que dejaban de contemplarse en el planeamiento como un coste del enclave turístico y que a la postre redundaría en un gasto para las arcas públicas por las demandas de servicios por parte de los titulares de propiedades en el Centro, acostumbrados a un nivel de prestación de servicios en el que no se hacía excepción por las particularidades del asentamiento.

Esta facilidad para la inversión, para la obtención de inmediatos rendimientos con postergación de costes que hubieron de afrontarse años más adelante, es un problema que existe en la realidad actualmente en muchos Centros, que mantienen en sus respectivos municipios una situación de urbanizaciones pendientes de ultimar, una constante reivindicación de inversiones y de prestación de servicios.

\section{El devenir de la norma: las reformas de la normativa urbanística y la promulgación de la Constitución española.}

La LCyZITN dio lugar a la creación de más de sesenta enclaves turísticos a lo largo de la geografía nacional, con una preeminencia de los situados en la costa y más concretamente en la vertiente mediterránea, con lo que el instrumento sirvió, como decimos, más que para encauzar y controlar el crecimiento, para crear un nuevo modelo, materializado en la posibilidad de implantación de enclaves urbanos, no aledaños a núcleos urbanos ni en sus inmediaciones. Como sostienen los Profs. Galiana Martín y Barrado Timón "En todo caso, la ubicación de los centros sirvió en buena medida para ampliar la colonización turística de lugares hasta ese momento apenas desarrollados: es el caso del litoral sur de Tenerife, en

\footnotetext{
${ }^{7}$ QUINTERO SANTOS, J. L.: Los impactos económicos, socioculturales y medioambientales del turismo y sus vínculos con el turismo sostenible, en Anales del Museo de América, n 12, 2004.

${ }^{8}$ GALIANA MARTÍN, L; BARRADO TIMÓN, D.: Los Centros de Interés Turístico Nacional y el despegue del turismo de masas en España. Investigaciones Geográficas, $n^{\circ} 39$ (2006) pp. 73-93. Instituto Universitario de Geografía. Universidad de Alicante.
} 
Canarias; de Menorca, en Baleares; o incluso de Marbella, donde el gran centro de Nueva Andalucía (el mayor de todos) supuso el detonante del posterior proceso urbanizador del municipio, además de otorgarle una inequívoca imagen de calidad que ha mantenido hasta la actualidad."

La Ley tuvo un cierto éxito en cuanto a la declaración de Centros de Interés Turístico, no así en lo relativo a las Zonas de Interés turístico. El "IV Plan de Desarrollo Económico (1976-1979)”, elaborado entre 1973 y 1974y que no llegó a ser aprobado por el avenimiento de la democracia todavía se refería a los Centros y Zonas de Interés Turístico como "figura clave para una correcta ordenación del territorio", pero ofreciendo datos que ponían de manifiesto que el instrumento de planificación no había funcionado: en 1974 sólo se habían declarado 71Centros de Interés Turístico en todo el territorio nacional y únicamente se habían realizado treinta y dos operaciones de uso del crédito para la financiación de obras de infraestructura turística previstas en la Orden del Ministerio de Hacienda de 3 de julio de 1964 reguladora de la concesión de créditos por el Banco Hipotecario de España para la realización de obras de urbanización e infraestructura en Centros y Zonas de interés turístico nacional ${ }^{10}$.

La virtualidad de la norma quedó mermada definitivamente por la entrada en vigor de la Ley del Suelo de 1975 y más adelante con la distribución de competencias establecidas en la Constitución entre el Estado y las Comunidades Autónomas y sobre todo por el reconocimiento de la autonomía local y las competencias asumidas por los ayuntamientos tras la Ley de Bases de Régimen Local de 1985.

Durante la vigencia de la LCyZITN y de su reglamento, se pueden diferenciar dos etapas. La primera hasta la entrada en vigor de la Ley 19/1975, de 2 de mayo, de reforma de la Ley sobre Régimen del Suelo y Ordenación Urbana de 12 de mayo de 1956, y una segunda, con posterioridad a dicha Ley. En la primera etapa, en virtud de las disposiciones finales $1 .^{\mathrm{a}} \mathrm{y}$ 2. ${ }^{a}$ de la LCyZITN, esta tenía una aplicación preferente a la Ley sobre Régimen del Suelo y Ordenación Urbana de 12 de mayo de 1956, que sólo era de aplicación supletoria en cuanto a lo que no se encontrase regulado en ella y fuese de aplicación. Los Planes de Ordenación Urbana de los Centros de Interés Turístico Nacional podían aprobarse aunque no existiese planeamiento general, o si lo había, en contradicción con el mismo. Eras planes que podían tener la denominación de planes especiales o parciales, pero que realmente eran planes excepcionales porque mantenían una total independencia con el planeamiento.

Tras la Ley del Suelo de 1975, la disposición final 3. ${ }^{a}$ y disposición transitoria 5. 4 de la misma, y más concretamente en la tabla de vigencias y disposición transitoria $5 .^{a} 4$ del Texto Refundido de la Ley sobre Régimen del Suelo y Ordenación Urbana aprobado por Real Decreto 1346/1976, de 9 de abril se alteraron los roles, de tal manera que la normativa urbanística era de aplicación preferente a la LCyZITN, cuyas disposiciones urbanísticas debían plegarse a las de la Ley del Suelo y Ordenación Urbana para luego dar lugar a un texto refundido que nunca vería la luz. Con ello, los Planes de Ordenación de los Centros de

\footnotetext{
${ }^{9}$ GALIANA MARTÍN, L Y BARRADO TIMÓN, D.: Los centros de interés turístico nacional y el despegue del turismo de masas en España. Investigaciones Geográficas, nº 39 (2006) pp. 73-93. Instituto Universitario de Geografía. 2006, Universidad de Alicante.

${ }^{10}$ VELASCO GONZÁLEZ, Ma , La política turística. Gobierno y Administración Turística en España (19522004), Tirant lo Blanch. Valencia 2004.
} 
aprobación posterior, y también las modificaciones o revisiones de los anteriores, si tenían contenidos urbanísticos, debían redactarse conforme a las determinaciones de la Ley del Suelo de 1975 y posterior Texto Refundido de 1976, aun con el mismo régimen de competencias previsto en la LCyZITN, que se vería alterado tras la Constitución Española de 1978 y la Lay de Bases de Régimen Local. De hecho y de derecho la virtualidad urbanística de la norma había terminado.

El Decreto 2842/1974, de 9 de agosto, de Medidas de Ordenación de la Oferta Turística, intentó establecer criterios para alcanzar una cierto equilibrio entre el desarrollo turístico y las infraestructuras que el sector precisaba y los recursos naturales necesarios, acomodando la oferta turística en sus aspectos cualitativo y cuantitativo a las condiciones de la demanda actual y potencial. Previó para ello dos instrumentos: la declaración de "territorios de preferente uso turístico" por el Gobierno a propuesta del Ministerios de Información y Turismo; y el procedimiento de urgencia para la declaración de Centros de Interés Turístico Nacional en aquellas demarcaciones territoriales municipales en las que se diesen cualificadas circunstancias que demandasen una acción ordenadora o promocional de carácter turístico, a través de ayudas económicas al sector inmobiliario en forma de subvenciones directas, créditos hoteleros, etc ${ }^{11}$.

En cuanto al régimen de competencias, fue, como decimos, definitivamente recuperado por los Ayuntamientos de acuerdo con las previsiones de la Ley del Suelo, en lo que respecta a los Planes de Ordenación Urbana y Programas de Actuación Urbanística y, en su caso, las Normas Complementarias y Subsidiarias del Planeamiento, conforme al procedimiento previsto en la legislación de Régimen Local, careciendo de sentido no ya un informe vinculante del Ministerio con competencias en materia de turismo, sino de la correspondiente Comunidad autónoma en el caso de que hubiera asumido la competencia sobre el turismo, como generalizadamente ocurriría posteriormente.

La Ley 28/1991, de 5 de diciembre, que derogó la LCyZITN terminó con el escaso contenido que permanecía vigente de la LCyZITN, ya sin virtualidad alguna. Pero los efectos de su regulación quedaban en los municipios y comarcas donde se habían implantado los Centros, pero la Ley preveía en una Disposición Transitoria que los beneficios concedidos a los Centros de Interés Turístico de conformidad con las previsiones de la Ley167/1963 subsistieran "condicionados en su disfrute al cumplimiento de las normas y requisitos en cuya virtud fueron concedidos".

La Constitución Española de 1978 establecía la posibilidad de que las Comunidades Autónomas asumiesen competencias sobre ordenación del territorio, urbanismo y vivienda (art. 148.1.3 ${ }^{\mathrm{a}} \mathrm{CE}$ ), y sobre promoción y ordenación del turismo dentro de su ámbito territorial (art.148.1.18 $\mathrm{CE}$ ), como de forma generalizada han hecho todas ellas. Asimismo la Ley 22/1988, de 28 de julio, de Costas derogó diversos artículos relativos a los efectos y beneficios de la declaración de interés turístico relacionados con el dominio público-marítimo terrestre.

La regulación de la actividad turística auspiciada por la LCyZITN carecía de la necesaria coordinación con la normativa urbanística y con sus principios, esencialmente con los de sostenibilidad del desarrollo urbano y equidistribución de beneficios y cargas. Los

\footnotetext{
11 ZARAGOZA ORTS, P., “Actuaciones administrativas. 1972-1982”, en 50 años del turismo español. Un análisis histórico y estructural, BAYÓN MARINÉ, F. (Dir.) et al, Centro de Estudios Ramón Areces, 1999.
} 
términos se invirtieron al permitir un desarrollo turístico a ultranza desatendiendo que es una actividad que consume territorio y determina la implantación de servicios públicos inherentes a cualquier asentamiento humano. Se desecharon otras posibilidades que ofrecía la normativa urbanística, como Planes Parciales, Especiales, Actuaciones puntuales... implantando unos criterios tendentes al desarrollo de la actividad turística y supeditando a la misma las determinaciones territoriales. Esta alteración de los términos naturales del sistema, del turismo sobre el territorio, o los intereses económicos sobre los territoriales fue acompañada como vimos de una alteración de la distribución natural de competencias entre los órganos administrativos $^{12}$.

Si desde el punto de vista del desarrollo turístico la LCyZITN fue aplaudida por promotores e inversores, extranjeros muchos de ellos, desde las premisas del urbanismo fue muy criticada ya que suponía el desarrollo de una política sectorial coyuntural al margen de una concepción global de la ordenación territorial y de los instrumentos propios de esta actividad administrativa ${ }^{13}$.

El Ministerio de Información y Turismo impuso su gestión sobre la Administración responsable del territorio (ayuntamientos, Ministerio de la Vivienda...) de tal manera que la intervención administrativa en la economía se verificaba en unos términos de plena disponibilidad sobre los recursos esenciales que estaban llamados a ser gobernados desde premisas puramente administrativas y conforme a los fines del interés general inherente a las mismas."No sólo se utilizan unas técnicas urbanísticas fuera del contexto que les es propio y para unos fines no urbanísticos, alterando para ello su régimen jurídico, sino que el empleo de dichas técnicas se impone precisamente a un Órgano de la Administración urbanística"14.

Esta completa pérdida de control por parte de los municipios de los desarrollos urbanísticos turísticos en sus territorios provocará importantes conflictos en la gestión del suelo, la implantación de las infraestructuras y la prestación de los servicios públicos. No queremos decir que los Centros y Zonas de interés turísticos se crearan pese a la oposición de los municipios en cuyos términos territoriales se ubicaron, pero sí que el modelo propició un desarrollo que desatendía las consecuencias territoriales y para los servicios que implicaba. Ha de reconocerse que muchos Centros supusieron un motor económico para muchos municipios, siendo fuente de ingresos, cuando no de financiación, de unas arcas municipales que empezaban a padecer un desfase notable entre los ingresos y el cada vez más importante aumento de los gastos a que debían hacer frente.

Esta actuación administrativa que describimos solo tiene cabida en un escenario de ausencia de democracia. Solo cuando los ciudadanos que habitan los territorios están desprovistos de la facultad de elegir a sus gobernantes es posible la intervención administrativa decididamente favorecedora de desarrollos económicos coyunturales determinantes de desequilibrios regionales. En este sentido resultan reveladoras las

\footnotetext{
${ }^{12}$ RAZQUIN LIZÁRRAGA M. Ma., "Planificación turística y planificación territorial: la necesidad de una convergencia”, en Ordenación y gestión del territorio turístico, Blanquer Criado, D. (Dir.), Tirant lo Blanch, 2002.

${ }^{13}$ PÉREZ ANDRÉS, A. A., “20 años de ordenación del territorio y urbanismo en Andalucía”, en la Revista Andaluza de Administración Pública, nº 2, 2003.

${ }^{14}$ PAREJ0, L.: La ordenación urbanística. El periodo 1956-1975. Montecorvo S.A. Madrid. 1979.
} 
conclusiones contenidas en el Dictamen de la Comisión Europea de 1978 sobre nuestra solicitud de ingreso en la Comunidad Económica Europea ${ }^{15}$ sobre esta cuestión donde se pone de manifiesto la existencia de notables desequilibrios regionales fruto de una intervención administrativa que no perseguía la distribución igualitaria de la riqueza y la solidaridad entre los territorios sino unos resultados globales aunque fuera con el sacrificio de unos por otros. El mismo modelo es el que propició la creación de los Centros y Zonas de interés turístico: por un desarrollo de la actividad turística que iba a solucionar a corto plazo los graves desequilibrios de la economía española se crearon enclaves urbanos que, ciertamente generaron beneficios, pero una desigual distribución de los mismos y un impacto territorial definitivo al margen de lo que pudieran decidir los habitantes de dichos territorios.

\section{Los Centros de Interés Turístico en Andalucía}

En Andalucía, según el Archivo General de Andalucía ${ }^{16}$ se crearon 30 Centros: 5 en la provincia de Málaga, 9 en la de Cádiz, 4 en Huelva, otros tantos en Almería y Granada y 1 en Sevilla. La mayoría se situaron en zonas costeras y conformaron un producto más del turismo de sol y playa, sobre todo en zonas que no experimentaban un crecimiento tan desaforado como el que experimentaba la Costa del Sol. Así, en la costa de Cádiz la mayoría se ubicó en el Campo de Gibraltar, como una ampliación de la Costa del Sol. Con desigual suerte se crearon los Centros de Guadacorte en Los Barrios, La Alcaidesa y Sotogrande en San Roque, Horizonte de Quintana en Algeciras, Cabo de Plata y El Cuartón en Tarifa y Los Portichuelos en La Línea.

En Huelva, los cuatro se ubicaron en la costa dando lugar a un extraordinario crecimiento del turismo, sobre todo de interior (Isla Canela en Ayamonte, El Portil en Cartaya, Matalascañas en Almonte y Mazagón en Palos de la Frontera) ${ }^{17}$.

Tanto los Centros de Cádiz como los de Huelva tenían una finalidad claramente desarrollista, de fomento de asentamientos turísticos en zonas que no habían sufrido aún los efectos del boom turístico que ya había hecho estragos en la Costa del Sol malagueña.

En principio, los que se crearon en Málaga surgieron con la finalidad de ordenar el desarrollo turístico y hacerlo compatible con un diseño territorial ordenado, evitando la diseminación en pequeños núcleos o urbanizaciones privadas. Así surgieron los Centros Nueva Andalucía y Pinomar en Marbella, Torremuelle en Benálmadena y Benahavís en el municipio homónimo. El resultado no fue, qué duda cabe, el pretendido, toda vez que los Centros lo que hicieron fue sumar impacto territorial al desaforado crecimiento que siguió su curso sin que la actividad administrativa pudiera reordenarlo.

\footnotetext{
${ }^{15}$ Opinion on Spain's Application for Membership. Transmitted to the Council by the Commission on 29 November 1978. COM (78) 630 final, 30 de noviembre de 1978. Bulletin of the European Communities, Suplemento 9/78.

${ }^{16}$ Código de referencia: ES.410917.AGA/1.5.2.1. Título: Expedientes de declaración de Centros de Interés Turístico Nacional (CITN) Fechas: 1963-1987. Nivel descripción: Serie. Volumen y soporte: 196 cajas. Nombre del productor: Consejería de Turismo

17 SANTOS PAVÓN, E., La actividad turística en la costa occidental de Huelva: estructuración sectorial y sostenibilidad territorial, Patronato Provincial de Huelva, 1999.
} 
En Almería se crearon los de Roquetas y Aguadulce en Roquetas del Mar, El Oasis de la Costa del Sol en Dalias y Las Marinillas en Almería, y en Granada, Playa de Granada, en Motril. En estos casos, lo que se promovió fue una urbanización intensísima del litoral, en detrimento de un modelo tendente a la articulación con el interior.

Otros Centros se ubicaron en el interior, para desarrollar un incipiente turismo alternativo al de sol y playa. Fueron tres los Centros de Interés Turístico Nacional de esta clase declarados en Andalucía (Las Navas de San Luis en Parauta, El Santiscal en Arcos de la Frontera y Parque de Cubillas en Albolote).

El Serrallo y Soly Nieve, en Granada eran Centros dedicados al turismo invernal, de nieve. El primero de los cuales ha generado y sigue generando una notable litigiosidad con motivo de la integración del enclave en la ciudad y de la prestación de los servicios públicos y ello pese a la capacidad de una ciudad como Granada para integrarlo en su red de servicios.

Existen por último algunos centros cuya finalidad sería la de servir de segundas residencias a grandes centros urbanos, como Las Pajanosas en Sevilla, enfocado a un turismo de fin de semana.

El sistema auspició un desarrollismo del turismo de sol y playa, con un intensísimo consumo territorial al margen de cualquier planificación. Bajo el principio de "cuanto más mejor" la intervención administrativa no solo gestionaba el turismo, sino el territorio. Esta afectación territorial se verificó "desde la gestión turística" mediante instrumentos y procedimientos con trámites menos garantistas, plazos de tramitación más cortos, que no priorizaban los aspectos urbanístico ${ }^{18}$. Los Planes de Ordenación Urbana previstos para los Centros tenían notables diferencias con respecto a los regulados en la Ley del Suelo y Ordenación Urbana de1956, pero los Planes Parciales previsto en el art. 10 de la Ley eran muy similares con la diferencia de que los elaborados al amparo de la LCyZITN primaban frente a los aprobados ex legislación urbanística, hasta la reforma de la legislación urbanística de $1975^{19}$.

Esa fragilidad procedimental sirvió en no pocas ocasiones, para la invasión del dominio público marítimo terrestre o para la consolidación de suelo urbano irregular ${ }^{20}$. El desarrollo urbanístico de los municipios se vio condicionado por la realidad de los Centros que se habían implantado, de forma que tenían que integrar, no pocas veces de forma descoordinada y con gran litigiosidad la realidad urbanística creada desde la actividad turística. Esto es una realidad aún latente en Centros como Atlanterra en Tarifa o El Serrallo en Granada.

Los Centros creaban además desequilibrios “a favor del municipio”. Constituían y constituyen una fuente de financiación proveniente de los impuestos y tasas que de los mismo se perciben para unos Ayuntamientos que, en dificultades, poco podían corresponder con la prestación de servicios públicos, muy costosos, no ya por la localización del enclave sino por

${ }^{18}$ SÁNCHEZ BLANCO, A., La afectación de bienes al dominio público, Instituto García Oviedo (Sevilla), 1978.

${ }^{19}$ VERA FERNÁNDEZ-SANZ, A. "La ordenación de playas y otros espacios costeros”, Revista Española de Derecho Administrativo (REDA), no 27, octubre-diciembre, 1980.

${ }^{20}$ Tribunal Supremo (Sala de lo Contencioso-Administrativo, Sección 5a) Sentencia de 21 junio 2005. Sobre la consideración de suelo urbano o urbanizable en el CIT Atlanterra. 
la evidencia de tener que implementar los mismos a una masa de población importante de manera inmediata y que además los utiliza puntualmente en temporadas muy concretas.

\section{El instrumento de planificación administrativa “municipio turístico" y el modelo que subyace a la creación de Centros y Zonas de Interés Turístico Nacional}

Como de forma muy pormenorizada estudió el Prof. Román Márquez en su tesis doctoral $^{21}$, no puede establecerse "prima facie” una similitud entre la ordenación propiciada por la figura de los Centros y Zonas de Interés y cualquier instrumento actual de ordenación y fomento de la actividad turística, más en concreto de la figura del municipio turístico contemplada actualmente en los arts. 19 y 20 de la Ley 13/2011, de 23 de diciembre, del Turismo de Andalucía.

Si bien es cierto que aparentemente ambas figuras surgen de la necesidad de dar respuesta al mismo problema de colapso del territorio por la afluencia turística, hemos visto que realmente la desregulación auspiciada por la normativa de los Centros y Zonas de interés turístico lo que provocaba, y quizás buscaba, era el efecto contrario.

Si en un principio tanto los Planes de Centros y Zonas como los convenios previstos como efecto a la declaración de "municipio turístico" en el art. 20.4 de la Ley del Turismo de Andalucía deben remediar el sobrecoste de servicios públicos, las diferentes perspectivas de un instrumento y otro son notables, y así el Prof. Román destaca que mientras que la declaración de Municipio Turístico respeta las premisas “municipales” de la declaración, ajustándola al ámbito del término municipal, en el caso de los Centros y Zonas de Interés Turístico Nacional, esto no era así. Por otro lado, los Centros tenían como finalidad evitar los errores de la sobreexplotación en futuros proyectos, premisa contraria de la que parte el municipio turístico, que está llamado a dar respuesta a los problemas ya creados en un destino preeminentemente turístico.

Los "planes de promoción turística" de los Centros no eran simplemente lo que su nombre enunciaba, sino que contenían determinaciones sobre el planeamiento, la ordenación del territorio y del urbanismo. Nada de esto ocurre en los casos de los municipios turísticos. La declaración de "municipio turístico" no altera las competencias y procedimientos urbanísticos.

Tampoco la figura del municipio turístico, u otros instrumentos de planificación turística de Andalucía supone una dejación de facultades públicas en detrimento de la iniciativa privada, o la sumisión de la actividad económica a las previsiones que contuviera el plan. Se llegaba, recordemos, en las ZITs a la posible constitución forzosa de agrupaciones de municipios comprendidos dentro de las mismas.

Hemos de discrepar no obstante de que "el legislador de 1963 y el actual Autonómico partan de una misma situación fáctica y pretendan lograr el mismo objetivo" si este objetivo lo materializamos en la ordenación y racionalización del fenómeno turístico

Un análisis del proceso de creación de la LCyZITN, de las tensiones que hubo de superar con el Ministerio de la Vivienda; del contenido de la misma norma, que antepuso la desregulación, los intereses privados y las necesidades económicas coyunturales a la gestión

\footnotetext{
${ }^{21}$ ROMAN MÁRQUEZ, A. El Municipio Turístico. Régimen jurídico y propuestas para su mejora. Tesis doctoral. Editorial de la Universidad de Granada 2008.
} 
de los recursos naturales y el territorio; y el devenir normativo de la misma, nos deben llevar a la conclusión de que solo formalmente el legislador de 1963 pretendió la ordenación y control del sector, en vez del desarrollo más intenso del mismo, abriendo nuevas vías al crecimiento, más concretamente las que proporcionaba un mecanismo de creación "ex novo" de enclaves urbanos con destino exclusivamente turístico, abriendo asimismo las posibilidades de inversión del capital extranjero. Lejos de ordenar o racionalizar, el modelo propuesto vino a abrir un nuevo frente en el despiadado proceso de consumo por parte de la actividad turística de recursos esenciales, con grave alteración de la ordenación territorial.

Ciertamente hemos de compartir con el Prof. Román que una actividad administrativa y otra, aquella de 1963 y esta reciente de planificación del turismo mediante los instrumentos que de forma generalizada contemplan todas las leyes del turismo de las diversas Comunidades Autónomas, son muy distintas, pero sin embargo podemos reconocer en ambas un mismo espíritu avieso: desplegar una intervención administrativa tendente al mantenimiento e intensificación de una actividad económica, la turística, anteponiendo las demandas y necesidades coyunturales que la misma exige y determina sobre la gestión de bienes e intereses que deberían determinar de forma prioritaria el diseño de las políticas públicas de intervención, fomento y servicios.

Desde estas premisas, un mecanismo y otro, el que permitió el desarrollo económico turístico mediante la creación de aquellos Centros y Zonas, y el que lo permite ahora mediante la adaptación de la política presupuestaria, medidas de fomento y de establecimiento de servicios públicos son manifestaciones de una misma filosofía que a lo largo de los años ha dado resultados no por dulces a corto plazo, menos amargos en el medio y largo plazo.

Aquella regulación de 1963 y esta actual del municipio turístico son muy dispares. No sería pensable hoy día, una intervención de tal naturaleza. Y siendo distintos también sus fines: claramente expansivos aquellos y más ordenadores estos en vigor, en ambas podemos encontrar una mismo fundamento si nos adentramos en la actual respuesta que se dispensa a la realidad turística de un municipio.

Por un lado, la calificación de "turístico" de un municipio no tiene un significado unívoco en nuestro Ordenamiento. Por una parte existe una consideración de "municipio turístico" en el Real Decreto Legislativo 2/2004, de 5 de marzo, por el que se aprueba el texto refundido de la Ley Reguladora de las Haciendas Locales (TRLHL), que prevé en su art. 125 ciertos beneficios para los municipios turísticos, a los que se conceptúa como aquellos que no sean capitales de provincia, o de comunidad autónoma yque no tengan una población de derecho igual o superior a 75.000 habitantes (arts. 125, 122 y 111 del TRLRHL) y en los que concurran además dos condiciones: a) Tener una población de derecho superior a 20.000 habitantes y b) Que el número de viviendas de segunda residencia supere al número de viviendas principales.

A los efectos de determinar la participación en los impuestos del Estado, la normativa presupuestaria reconoce el desequilibrio que el fenómeno turístico implica en el presupuesto de cualquier Ayuntamiento medio y establece un mecanismo excepcional para compensarlo.

Esta previsión del TRLHL se hace en sintonía con el art. 30 de la Ley de Bases de Régimen Local que prevé que las leyes sobre régimen local de las Comunidades Autónomas puedan establecer regímenes especiales para Municipios con predominio en su término de las actividades turísticas. La Ley 5/2010, de 11 de junio, de Autonomía Local de Andalucía no ha previsto un régimen especial para los municipios que por razón del predominio en su término de actividades turísticas sean merecedores de un régimen especial en la conformación de su 
organización, gobierno o financiación. La normativa presupuestaria y de régimen local apuntan el establecimiento de un régimen para remediar las consecuencias indeseadas de una realidad.

Por otro lado, esta previsión de la normativa presupuestaria tendente a paliar, a corregir, los desequilibrios en la financiación de los servicios públicos, implantación de infraestructuras, etc., convive con una normativa sectorial, turística, en nuestro caso, la Ley 13/2011, de 23 de diciembre, del Turismo de Andalucía que prevé una declaración de "municipio turístico" que sirva de cauce de ordenación y fomento de la actividad turística en los municipios en los que concurran los requisitos previstos en la Ley y desarrollados en el Decreto 158/2002, de 28 de mayo, de Municipio Turístico, modificado por el Decreto 70/2006, de 21 de marzo, que regula los requisitos y el procedimiento necesarios para acceder a la declaración de Municipio Turístico. La consecuencia de esta declaración no es la adaptación de la financiación del municipio a los desequilibrios y sobrecostes de servicios que provoca la actividad turística desproporcionada en los mismos, sino la posibilidad de celebrar convenios con la Administración autonómica como vía de financiación coyuntural para remediar los mismos desequilibrios que pretende enjugar la normativa presupuestaria, pero también para aumentar, diversificar y mejorar la oferta turística complementaria, así como crear nuevos productos (art. 13.2 e) del Decreto 158/2002.De hecho la reforma operada en el reglamento por el Decreto 70/2006 estuvo motivada en parte para "concretar aquellos servicios públicos que por su clara repercusión en la percepción del turista deben potenciarse y mejorarse así como incluirse en los convenios que se celebren con la Administración turística”.

De alguna manera, el desequilibrio que reconoce y pretende corregirse por una parte por el TRLRHL, se incrementa por otra, estableciendo las bases e instrumentos para ello. Otra vez se encuentra en el fomento del turismo, en la constante creación de productos turísticos un recurso económico incluso en aquellos escenarios donde la actividad turística es ya preeminente a cualquier otra; y otra vez procedemos de tal manera para solucionar los efectos de una situación de crisis económica que insistimos en remediar, no atajando los problemas de raíz que la originaron, sino encontrando rendimientos donde los haya, aunque procedan de sectores extenuados con una presencia desproporcionada en nuestra economía.

\section{Conclusiones}

La intervención pública en la actividad turística propiciada en los años sesenta y setenta por la Ley de Centros y Zonas de Interés Turístico Nacional se explica por una situación de crisis económica estructural que se intentaba paliar permitiendo una actividad turística con usos intensivos de recursos, insostenible y con una irreversible afectación territorial y de los recursos naturales.

Para proceder de tal forma, el instrumento de intervención subvertía el sistema de atribución de competencias entre los órganos administrativos, de tal manera que a la Administración competente en materia de promoción y gestión turística se le atribuyeron competencias en materia de ordenación del territorio, y fomento y gestión de infraestructuras y sistemas generales, relegando las competencias de otros órganos administrativos, como el Ministerio de la Vivienda y de otras administraciones públicas, como la local.

Así mismo se alteró la ordenación axiológica de bienes e intereses que debe presidir la gestión de los intereses generales. Recursos y bienes de carácter esenciales (ordenación del 
territorio en general, gestión del agua, de la costa, ordenación urbanística y diseño de infraestructuras...) se relegaron a las necesidades coyunturales inmediatas de la economía. Por otro lado, el equilibrio y la ordenación en el ámbito local se sacrificaron en pos de la obtención de ingresos de los que precisaba el conjunto de la economía española.

Tal política económica solo es posible en un sistema no democrático, donde los sujetos que habitan los territorios en los que se mantienen las condiciones de desigualdad no son sujetos de derechos políticos.

Aquella intervención administrativa determinó la creación de enclaves de población que en la actualidad generan una notable problemática a los municipios en cuyos términos territoriales radican. Implican dificultad para la prestación de los servicios públicos, para la contribución al coste de los mismos, para la implantación de las infraestructuras (abastecimiento de agua y depuración, accesos...), para el desarrollo y ejecución del planeamiento y para la ejecución y recepción de las urbanizaciones.

Aquel modelo de ordenación y fomento dista mucho del actualmente vigente, configurado por los instrumentos de planificación económica de la actividad turística, y más concretamente por la figura de municipio turístico. No obstante lo anterior, en lo esencial, en postergar o condicionar la gestión de bienes e intereses en pos de la actividad turística como remedio para solucionar una situación económica de crisis estructural, pueden verse, en un modelo y en otro, importantes similitudes.

En la actualidad, la impronta turística de un municipio determina el reconocimiento, por un lado, de un inevitable sobrecoste en la gestión económica de los servicios públicos y desde esa premisa se ha articulado en la normativa presupuestaria un régimen excepcional, que está llamado a incrementar la financiación de aquellos municipios en los que la actividad turística implica este indeseable desequilibrio, que se atiende lógicamente en detrimento de los demás entes locales.

Simultáneamente, la normativa turística prevé como respuesta a esa misma impronta turística una intervención pública tendente a remediar dichos desequilibrios, ciertamente, pero también $\mathrm{y}$, sobre todo, a fomentar las inversiones que determinen un incremento de la actividad turística, mediante la creación de productos turísticos a partir de los recursos con que se cuente, lo que en definitiva incrementa artificialmente el impacto del turismo sobre las poblaciones con el desequilibrio que ello supone.

Tal política solo es explicable en una realidad económica víctima de una política auspiciada por la improvisación cortoplacista, desconsiderada con los recursos naturales y sociales, y dispuesta a obtener rendimientos donde sea posible en cada momento. 